\title{
Kajian eksperimen instalasi pompa seri dan paralel terhadap efisiensi penggunaan energi
}

\author{
Iman Syahrizal ${ }^{1 *}$, Daud Perdana ${ }^{2}$ \\ Jurusan Teknik Mesin, Politeknik Negeri Sambas ${ }^{1,2}$ \\ Jl. Raya Sejangkung, Sambas, Kalimanatan Barat, Indonesia \\ Email: imansyahrizal22@gmail.com¹, Daudp3rdana@yahoo.com²
}

\begin{abstract}
The pump is used to transfer liquid fluid from a low place to a high place or from one place to another with a certain distance and with a certain height. This study aims to figure the connection of series and parallel pumps to the discharge, pressure and pump power, and to figure the efficiency of series and parallel pumps with energy use. This study was conducted in a mechanical engineering major at Sambas State Polytechnic. The method used was three treatment experiments, including installing a single pump, a series pump installation, and a parallel pump installation. Observed changes are flow rate, water pressure, motor rotation, and electric current. The results showed that the series pump did not affect the discharge, but it affected the pressure and hydraulic power of the pump. While the parallel pump affects the increase in discharge but does not affect the pump pressure and hydraulic power. The results of pump calculations flow rate series $0.000450 \mathrm{m3} / \mathrm{sec}$, while the parallel pump flow rate $0.000769 \mathrm{~m} 3 / \mathrm{sec}$. The results of pump measurement pressure are $80 \mathrm{psi}$ series, while the parallel pump pressure is 40 psi. The calculation result of the hydraulic pump is 248.28 Watt series, while the parallel pump hydraulic power is 198.2 Watt. The power efficiency of series pumps is higher than the efficiency of parallel pumps. The efficiency of electric power when measuring flow rate at $70.53 \%$ series pump installations, parallel pump electrical power efficiency of $56.3 \%$. The efficiency of electric power when measuring series water pressure is $45.14 \%$, while the parallel pump's electrical power efficiency is $36.03 \%$.
\end{abstract}

Keywords: Efficiency, pump installation, series, parallel.

\begin{abstract}
Abstrak
Pompa digunakan untuk memindahkan fluida cair dari tempat yang rendah ke tempat yang tinggi atau dari suatu tempat ke tempat yang lain dengan jarak tertentu dan dengan ketinggian tertentu. Penelitian ini bertujuan untuk mengetahui hubungan pompa seri dan paralel terhadap debit, tekanan dan daya pompa, serta untuk mengetahui efisiensi pompa seri dan paralel terhadap penggunaan energi. Penelitian ini dilakukan di jurusan teknik mesin Politeknik Negeri Sambas. Metode yang digunakan adalah eksperimen dengan tiga perlakuan, diantaranya instalasi pompa tungal, instalasi pompa seri dan instalasi pompa paralel. Perubahan yang diamati adalah debit aliran, tekanan air, putaran motor dan arus listrik. Hasil penelitian menunjukkan pompa seri tidak berpengaruh terhadap debit, namun berpengaruh terhadap tekanan dan daya hidrolik pompa. Sedangkan pompa paralel berpengaruh terhadap peningkatan debit namun tidak berpengaruh terhadap tekanan dan daya hirolik pompa. Hasil perhitungan debit aliran pompa seri $0.000450 \mathrm{~m}^{3} / \mathrm{dt}$, sedangkan debit aliran pompa paralel $0.000769 \mathrm{~m}^{3} / \mathrm{dt}$. Hasil pengukuran tekanan air pompa seri 80 psi, sedangkan tekanan air pompa paralel $40 \mathrm{psi}$. Hasil perhitungan daya hidrolik pompa seri 248,28 Watt, sedangakan daya hidrolik pompa paralel 198,2 Watt. Efisiensi daya listrik pompa seri lebih tinggi dibanding efisiensi daya listrik pompa paralel. Efisiensi daya listrik saat pengukuran debit aliran pada instalasi pompa seri $70,53 \%$, efisiensi daya listrik pompa paralel 56,3\%.
\end{abstract}


Efisiensi daya listrik saat pengukuran tekanan air pompa seri $45,14 \%$, sedangkan efisiensi daya listrik pompa paralel $36,03 \%$.

Kata kunci: Efisiensi, instalasi pompa, seri, paralel.

\section{Pendahuluan}

Pada umumnya pompa digunakan untuk menaikkan fluida dari tempat yang rendah ke tempat yang lebih tinggi dengan menggunakan pipa [1]. Prinsip kerja pompa adalah membuat tekanan rendah pada saluran isap, sehingga fluida akan terisap masuk dan mengeluarkannya pada sisi tekan atau sisi keluar dengan tekanan yang lebih tinggi [2]. Pompa memiliki kegunaan yang sangat luas baik dikalangan rumah tangga ataupun industri. Desain sistem perpipaan menjadi sangat penting dan mempunyai efek yang sangat besar dalam kinerja pompa [3].

Beberapa penelitian tentang pompa telah dilakukan untuk meningkatkan kinerja pompa yang terbaik, diantaranya penelitian tentang analisis pengaruh variasi diameter pipa tekan pvc pada pompa aksial untuk kecepatan gaya dorong air. Penelitian ini bertujuan untuk menganalisa pengaruh ukuran pipa pvc yang menyatakan bahwa semakin kecil ukuran pipa pvc yang diambil maka semakin cepat gaya dorong air yang dihasilkan [4]. Penelitian lain membahas tentang pengaruh volume tabung tekan terhadap unjuk kerja pompa hidram yang menyatakan bahwa volume tabung tekan berpengaruh terhadap unjuk kerja pompa yang meliputi debit dan efisiensi [5]. Penelitian tentang analisis tekanan pompa terhadap debit air menyatakan bahwa semakin besar tekanan pompa yang diberikan maka debit air yang dihasilkan makin banyak [6]. Penelitian tentang optimasi tinggi tekan dan efisiensi pompa sentrifugal dengan perubahan jumlah sudu impeler dan sudut keluar impeler $\left(\beta_{2}\right)$ menggunakan simulasi computational fluida dynamics menyatakan bahwa makin besar jumlah sudu impeler maka makin besar pula efisiensi pompa yang dihasilkan. Dalam penelitian yang sama juga dinyatakan bahwa makin besar head maka semakin besar efisiensi pompa yang dihasilkan [7].

Selain untuk meningkatkan kinerja pompa, hal yang juga harus diperhatikan adalah efisiensinya. Efisiensi merupakan parameter yang sangat penting dalam merencanakan pompa karena berhubungan dengan penggunaan energi. Efisiensi pompa merupakan perbandingan daya yang diberikan motor listrik kepada pompa dengan daya yang diberikan pompa kepada fluida. Berkenaan dengan hal tersebut di atas, maka penulis ingin melakukan kajian terhadap efisiensi instalasi pompa seri dan paralel.

\section{Tinjauan Pustaka}

Pada suatu kondisi, dimana kapasitas atau head yang diperlukan tidak dapat dicapai dengan satu pompa saja, maka selanjutnya dapat digunakan dua pompa atau lebih untuk mencapai kondisi head dan kapasitas yang diperlukan, dengan merangkai pompa tersebut secara seri maupun paralel. Gambar berikut ini menunjukan kurva head-kapasitas dari pompa-pompa yang memiliki karaktersitik yang sama.

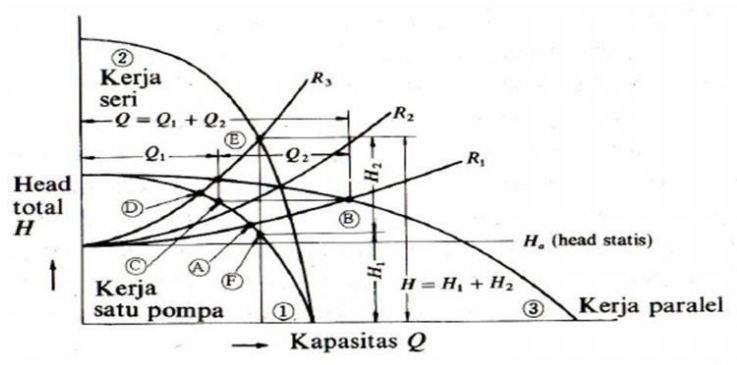

Gambar 1. Operasi seri dan paralel pompa karakteristik sama

Pada kurva karakterisitik diatas menunjukan pompa yang dipasang secara seri dan paralel. Dimana untuk pompa tunggal diberi tanda (1), pompa seri (2), dan pompa paralel (3). Ditunjukan tiga buah kurva dari head-kapasitas sistem, yaitu $R l$, $R 2$, dan $R 3$. Pada kurva $R 3$, menunjukan 
tahanan yang lebih tinggi dibandingkan dengan $R 1$ dan $R 2$. Jika sistem memiliki kurva head-kapasitas $R 3$, maka titik kerja pompa 1 akan terletak di D. Jika pompa disusun secara seri sehingga menghasilkan kurva 2, maka titik kerjanya akan berpindah ke E yang tidak sama dengan dua kali lipat head di D, karena ada perubahan yang berupa kenaikan kapasitas. Jika sistem memiliki kurva head-kapasitas $R l$ maka titik kerja pompa 1 akan terletak di A. Andaikan pompa disusun secara paralel sehingga menghasilkan kurva 3 maka titik kerjanya akan berpindah ke $\mathrm{B}$, disini dapat terlihat bahwa kapasitas di titik B tidak sama dengan dua kali lipat kapasitas pada titik A, karena ada perubahan kenaikan head sistem. Andaikan sistem memiliki kurva karakteristik seperti $R 2$, maka laju aliran akan sama untuk susunan secara seri ataupun paralel. Akan tetapi jika karakteristik sistem adalah $R 1$ dan $R 3$, maka akan diperlukan pompa susunan seri atau paralel. Jadi rangkaian seri digunakan untuk menaikan head, sedangkan paralel berguna untuk menaikan kapasitas aliran [8].

Debit pompa menunjukan kapasitas fluida yang mampu dialirkan pompa dalam satu satua waktu. Untuk menentukan debit yang dihasilkan oleh pompa dilakukan secara analitis.

Pengukuran debit dengan persamaan:

Keterangan:

$$
\boldsymbol{Q}=\frac{\mathrm{V}}{\boldsymbol{t}}
$$

$$
\begin{array}{ll}
\mathrm{Q} & \text { : Debit aliran (liter/detik) } \\
\mathrm{V} & \text { : Volume (liter) } \\
\mathrm{T} & \text { : Waktu (detik) }
\end{array}
$$

Head adalah suatu bentuk energi yang dinyatakan dalam satuan panjang (m) dalam SI. Head terdiri dari head ketinggian $(\mathrm{Z})$, head kecepatan $\left(\frac{v^{2}}{2 g}\right)$, dan head tekanan $\left(\frac{\mathrm{P}}{\rho \cdot g}\right)$. head ketinggian menyatakan energi potensial yang dibutuhkan untuk mengangkat air setinggi (m) kolom air, head kecepatan menyatakan energi kinetik yang dibutuhkan untuk mengalirkan air setinggi (m) kolom air. Sedangkan head tekanan adalah suatu energi aliran dari (m) kolom air yang memiliki berat sama dengan tekanan dari kolom (m) tersebut.

Hubungan antara tekanan dan head tekanan dapat dirumuskan seperti berikut:

$$
\mathrm{H}=\frac{\mathrm{P}}{\rho \cdot g}
$$

Keterangan:

$$
\begin{aligned}
\mathrm{Hp}= & \text { Head tekanan }(\mathrm{m}) \\
\mathrm{P}= & \text { Tekanan (Psi) } \\
\rho= & \text { Massa jenis air }\left(\mathrm{kg} / \mathrm{m}^{3}\right) \\
\mathrm{g}= & \text { Percepatan gravitasi } \\
& \left(\mathrm{m} / \mathrm{dt}^{2}\right)
\end{aligned}
$$

Daya adalah kerja yang dilakukan per satuan waktu. Satuan daya adalah HP atau Watt

a) Daya Hidrolik

Dapat hidrolik dapat dihitung dengan menggunakan persamaan:

Ppompa $=\rho \cdot g \cdot Q \cdot H$

Keterangan:

b) Daya Listrik

$$
\begin{aligned}
\rho= & \text { Massa jenis air }\left(\mathrm{kg} / \mathrm{m}^{3}\right) \\
\mathrm{g}= & \text { Percepatan gravitasi } \\
& \left(\mathrm{m} / \mathrm{s}^{2}\right) \\
\mathrm{Q}= & \text { Debit aliran }\left(\mathrm{m}^{3} / \mathrm{s}\right) \\
\mathrm{H}= & \operatorname{Head} \text { pompa }(\mathrm{m})
\end{aligned}
$$

Daya listrik dihitung dengan menggunakan persamaan:

Plistrik = V . I

Keterangan :

$$
\begin{aligned}
\mathrm{V} & =\text { Tegangan listrik }(\mathrm{V}) \\
\mathrm{I} & =\operatorname{Arus} \operatorname{listrik}(\mathrm{A})
\end{aligned}
$$

Efisiensi pompa adalah suatu faktor yang dipergunkan untuk menghitung energi kinetik yang hilang dalam bentuk losses atau kerugian. Efisiensi pompa terdiri dari :

1. Efisiensi hidrolis, memperhitungkan losses akibat gesekan antara cairan dengan impeler dan losis akibat perubahan arah yang tiba-tiba pada impeler.

2. Efisiensi

volumetris, memperhitungkan losses akibat resirkulasi pada ring, bushing, dll.

3. Efisiensi mekanis, memperhitungkan losis akibat gesekan pada seal, packing gland, bantalan, dll.

Efisiensi pompa akan mencapai maksimum pada designed point tersebut, 
yang dinamakan dengan titik BEP. Untuk kapasitas yang lebih kecil atau lebih besar efisiensinya akan lebih rendah. Efisiensi pompa adalah perbandingan antara daya hidrolik pompa dengan daya listrik.

$$
\eta=\frac{P_{\text {pompa }}}{P_{\text {listrik }}} \times 100 \%
$$

Keterangan:

$$
\begin{aligned}
\mathrm{P}_{\text {pompa }} & =\underset{\text { Daya }}{\text { (Watt })} \\
\mathrm{P}_{\text {listrik }} & =\text { Daya listrik }(\text { Watt })
\end{aligned}
$$

\section{Metode Penelitian}

Metode yang digunakan dalam penelitian ini adalah metode eksperimen dengan tiga tahap pengujian, diantaranya pengujian pompa tungal, pengujian pompa ganda dengan rangkaian seri dan pengujian pompa ganda dengan rangkaian paralel. Tahapan penelitian disusun dalam bentuk diagram alir seperti pada gambar 2 .

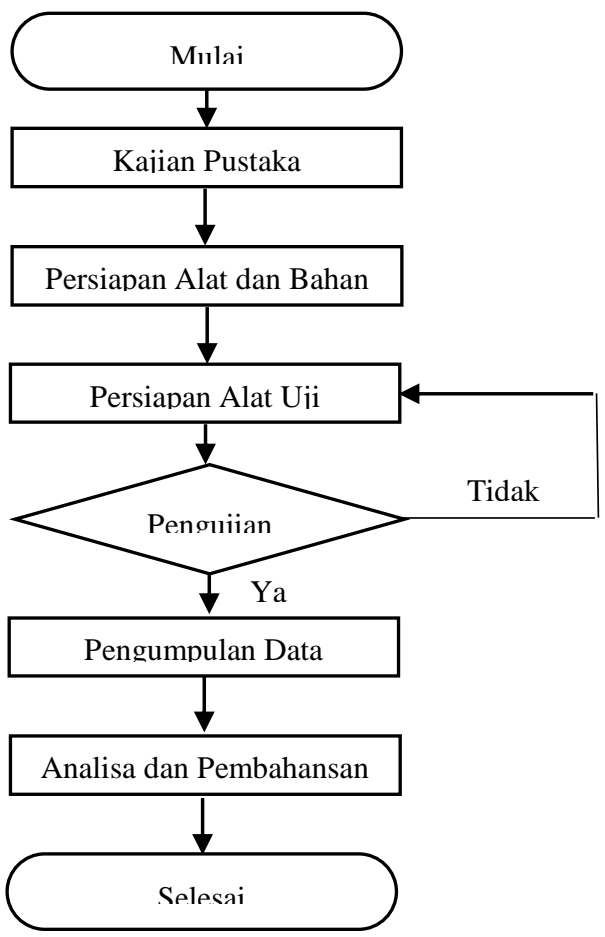

Gambar 2. Diagram alir penelitian

Penelitian dilakukan dengan menentukan variabel bebas dan variabel tak bebas. Variabel bebas penelitian ini adalah instalasi pompa tunggal, instalasi pompa rangkaian seri, dan instalasi pompa rangkaian paralel. Sedangkan yang menjadi variabel tak bebas adalah adalah debit aliran $(\mathrm{Q})$, tekanan air $(\mathrm{P})$, putaran motor penggerak (rpm), dan arus listrik (I). Rancangan penelitian ini dimulai dari persiapan alat uji, proses pengujian untuk mendapatkan data, melakukan analisis dan membuat kesimpulan.

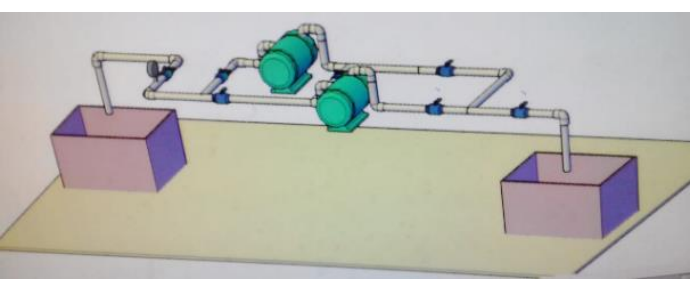

Gambar 3. Desain alat uji

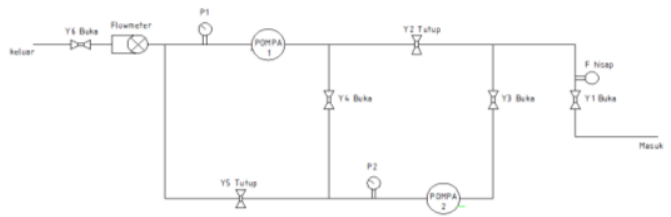

Gambar 4. Instalasi pompa seri

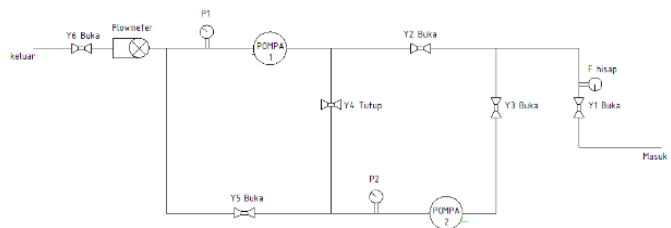

Gambar 5. Instalasi pompa paralel

\section{Hasil dan Pembahasan}

Hasil uji kinerja instalasi pompa

\begin{tabular}{|c|c|c|c|c|c|c|c|c|}
\hline \multirow{2}{*}{$\begin{array}{l}\text { Insta } \\
\text { lasi } \\
\text { pom } \\
\text { pa }\end{array}$} & \multirow{2}{*}{$\begin{array}{c}\text { Gay } \\
\text { a } \\
\text { hisa } \\
\text { p } \\
\text { po } \\
\text { mpa } \\
\text { (cm } \\
\text { hg) }\end{array}$} & $\begin{array}{l}\text { Vol } \\
\text { ume } \\
\left(\mathrm{m}^{3}\right)\end{array}$ & $\begin{array}{c}\text { Wa } \\
\text { ktu } \\
\text { (det } \\
\text { ik) }\end{array}$ & $\begin{array}{l}\text { Tega } \\
\text { ngan } \\
\text { listrik } \\
\text { (volt) } \\
\end{array}$ & \multicolumn{2}{|c|}{$\begin{array}{c}\text { Arus } \\
\text { listrik } \\
\text { (amper } \\
\text { e) }\end{array}$} & \multicolumn{2}{|c|}{$\begin{array}{c}\text { Putaran } \\
\text { (rpm) }\end{array}$} \\
\hline & & $\mathbf{v}$ & $\mathbf{T}$ & $\mathbf{V}$ & $\mathbf{I}_{1}$ & $\mathbf{I}_{2}$ & $\mathbf{N}_{1}$ & $\mathbf{N}_{2}$ \\
\hline $\begin{array}{l}\text { Pom } \\
\text { pa } 1 \\
\text { (tung } \\
\text { gal) }\end{array}$ & 0,8 & 0,01 & 22,9 & 220 & $\begin{array}{l}0, \\
8\end{array}$ & & $\begin{array}{l}28 \\
75\end{array}$ & \\
\hline $\begin{array}{l}\text { Pom } \\
\text { pa } 2 \\
\text { (tung } \\
\text { gal) } \\
\end{array}$ & 0.8 & 0.01 & 23.4 & 220 & & $\begin{array}{c}0 . \\
8\end{array}$ & & $\begin{array}{l}28 \\
77\end{array}$ \\
\hline $\begin{array}{l}\text { Pom } \\
\text { pa } \\
\text { seri } \\
\end{array}$ & 0,8 & 0,01 & 22,2 & 220 & $\begin{array}{c}0, \\
8\end{array}$ & $\begin{array}{c}0, \\
8\end{array}$ & $\begin{array}{l}28 \\
64\end{array}$ & $\begin{array}{l}28 \\
84\end{array}$ \\
\hline $\begin{array}{l}\text { Pom } \\
\text { pa } \\
\text { paral } \\
\text { el }\end{array}$ & 0,8 & 0,01 & 13 & 220 & $\begin{array}{c}0 \\
8\end{array}$ & $\begin{array}{c}0 \\
8\end{array}$ & $\begin{array}{l}28 \\
35\end{array}$ & $\begin{array}{l}28 \\
79\end{array}$ \\
\hline
\end{tabular}
tunggal, instalasi pompa rangkaian seri dan instalasi pompa rangkaian paralel terhadap debit aliran disajikan dalam tabel 1 . 
Tabel 1 menunjukkan bahwa waktu yang paling cepat untuk mendapatkan volume air sebanyak $0,01 \mathrm{~m} 3$ adalah pada instalasi pompa paralel yaitu 13 detik, sedangkan pada instalasi pompa seri waktu yang diperlukan untuk mendapatkan volume air sebanyak $0,01 \mathrm{~m} 3$ adalah 22,2 detik dan pada instalasi pompa tunggal 1 waktu yang diperlukan adalah 22,9 detik, pada instalasi pompa tunggal 2 adalah 23,4 detik. Ini berarti bahwa instalasi pompa paralel mampu untuk meningkatkan debit aliran dibanding instalasi pompa seri. Waktu yang diperlukan untuk mendapatkan volume air sebanyak $0,01 \mathrm{~m}^{3}$ pada instalasi pompa seri tidak jauh berbeda dengan waktu yang diperlukan pada instalasi pompa tunggal.

Hubungan antara instalasi pompa terhadap waktu untuk mendapatkan volume air disajikan dalam bentuk grafik pada gambar 6.

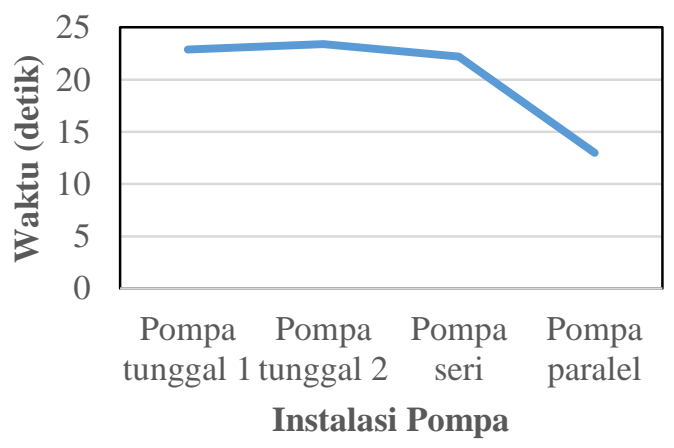

Gambar 6. Grafik waktu pencapaian volume air

Analisis perhitungan menggunakan persamaan 2.1 membuktikan bahwa instalasi pompa paralel mampu menghasilkan debit aliran yang lebih besar bila dibandingkan dengan instalasi pompa seri maupun instalasi pompa tunggal. Debit yang dihasilkan dari instalasi pompa paralel adalah $0.000769 \mathrm{~m}^{3} / \mathrm{dt}$, sedangkan debit aliran yang dihasilkan instalasi pompa seri adalah $0.000450 \mathrm{~m}^{3} / \mathrm{dt}$, dan debit aliran yang di hasilkan dari instalasi pompa tunggal adalah $0.000432 \mathrm{~m}^{3} / \mathrm{dt}$. Besarnya debit yang dihasilkan instalasi pompa paralel tidak sama dengan dua kali lipat debit yang dihasilkan instalasi pompa tunggal, hal ini terjadi karena ada pengaruh dari perubahan kenaikan heat sistem.

Hubungan antara instalasi pompa terhadap debit aliran diperlihatkan dalam bentuk grafik pada gambar 7 .

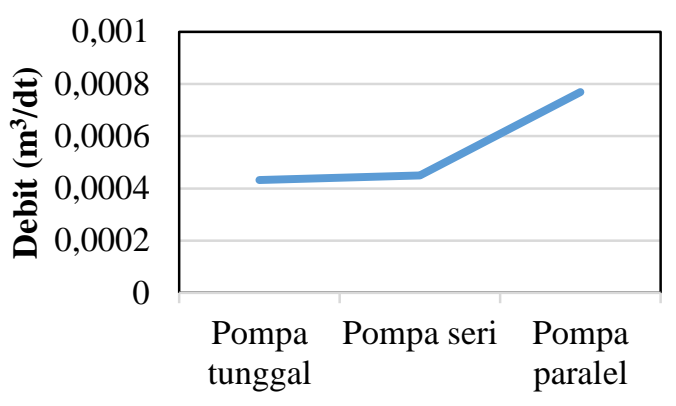

Instalasi Pompa

Gambar 7. Grafik debit aliran yang dihasilkan

Hasil uji kinerja instalasi pompa tunggal, pompa seri dan pompa paralel terhadap tekanan disajikan dalam Tabel 2.

Tabel 2. Data Pengujian Tekanan

\begin{tabular}{|c|c|c|c|c|c|c|c|}
\hline \multirow{2}{*}{$\begin{array}{c}\text { Instala } \\
\text { si } \\
\text { pompa }\end{array}$} & \multirow{2}{*}{$\begin{array}{c}\text { Gaya } \\
\text { hisap } \\
\text { pom } \\
\text { pa } \\
(\mathrm{cmh} \\
\mathrm{g})\end{array}$} & \multirow{2}{*}{$\begin{array}{c}\text { Tekan } \\
\text { an } \\
\text { (psi) }\end{array}$} & \multirow{2}{*}{$\begin{array}{l}\text { Tegan } \\
\text { gan } \\
\text { listrik } \\
\text { (volt) }\end{array}$} & \multicolumn{2}{|c|}{$\begin{array}{c}\text { Arus } \\
\text { listrik } \\
\text { (amper } \\
\text { e) }\end{array}$} & \multicolumn{2}{|c|}{$\begin{array}{c}\text { Putaran } \\
\text { (rpm) }\end{array}$} \\
\hline & & & & $\mathrm{I}_{1}$ & $\mathrm{I}_{2}$ & $\mathrm{~N}_{1}$ & $\mathrm{~N}_{2}$ \\
\hline $\begin{array}{l}\text { Pomp } \\
\text { a } 1 \\
\text { (tungg } \\
\text { al) }\end{array}$ & 0,4 & 40 & 220 & $\begin{array}{c}1, \\
1\end{array}$ & & $\begin{array}{l}24 \\
02\end{array}$ & \\
\hline $\begin{array}{l}\text { Pomp } \\
\text { a } 2 \\
\text { (tungg } \\
\text { al) }\end{array}$ & 0.4 & 40 & 220 & & $\begin{array}{l}1 . \\
2\end{array}$ & & $\begin{array}{l}25 \\
66\end{array}$ \\
\hline $\begin{array}{l}\text { Pomp } \\
\text { a seri }\end{array}$ & 0,4 & 80 & 220 & $\begin{array}{l}1, \\
1\end{array}$ & $\begin{array}{l}1, \\
4\end{array}$ & $\begin{array}{l}24 \\
66 \\
\end{array}$ & $\begin{array}{l}25 \\
63\end{array}$ \\
\hline $\begin{array}{l}\text { Pomp } \\
\text { a } \\
\text { paralel }\end{array}$ & 0,4 & 40 & 220 & $\begin{array}{c}1, \\
1\end{array}$ & $\begin{array}{l}1, \\
4\end{array}$ & $\begin{array}{l}22 \\
41\end{array}$ & $\begin{array}{l}25 \\
58\end{array}$ \\
\hline
\end{tabular}

Data pada tabel 2 menunjukkan bahwa tekanan yang paling besar terjadi pada instalasi pompa seri yaitu 80 psi, sedangkan tekanan pada instalasi pompa paralel sama dengan tekanan pada instalasi pompa tunggal yaitu 40 psi.

Hubungan instalasi pompa terhadap tekanan diperlihatkan dalam bentuk grafik pada gambar 8 . 


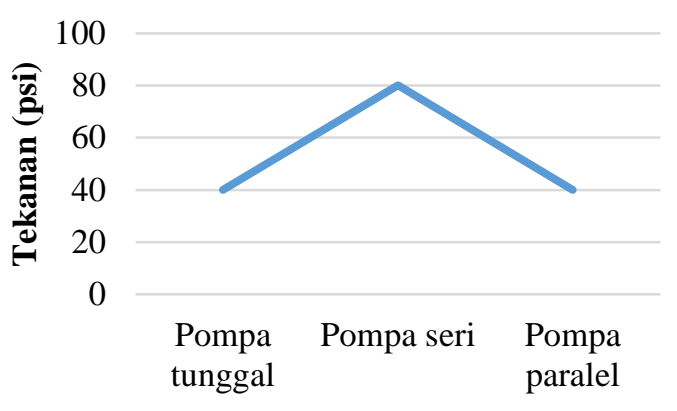

Instalasi Pompa

Gambar 8. Grafik tekanan pompa

Analisis perhitungan menggunakan persamaan 2.5 membuktikan bahwa efisiensi penggunaan daya listrik tertinggi saat pengukuran debit aliran adalah pada instalasi pompa seri yaitu 70,53\%, sedangkan efisiensi penggunaan daya listrik terendah adalah pada instalasi pompa paralel yaitu 56,3\%, dan efisiensi penggunaan daya listrik pada instalasi pompa tunggal adalah $63,26 \%$. Ini artinya bahwa instalasi pompa paralel mampu meningkatkan debit aliran tetapi penggunaan energi listriknya cukup besar karena efisiensinya rendah.

Efisiensi penggunaan daya listrik tertinggi saat pengukuran tekanan air terjadi pada instalasi pompa seri yaitu $45,14 \%$, sedangkan efisiensi penggunaan daya listrik terendah juga terjadi pada instalasi pompa paralel yaitu $36,03 \%$, dan efisiensi penggunaan daya listrik pada instalasi pompa tunggal adalah $44,00 \%$. Ini artinya bahwa instalasi pompa seri mampu untuk meningkatkan tekanan air, serta efisiensi penggunaan daya listriknya tinggi dibanding instalasi pompa paralel maupun pompa tunggal.

Hubungan instalasi pompa terhadap efisiensi daya listrik diperlihatkan dalam bentuk grafik pada gambar 9 .

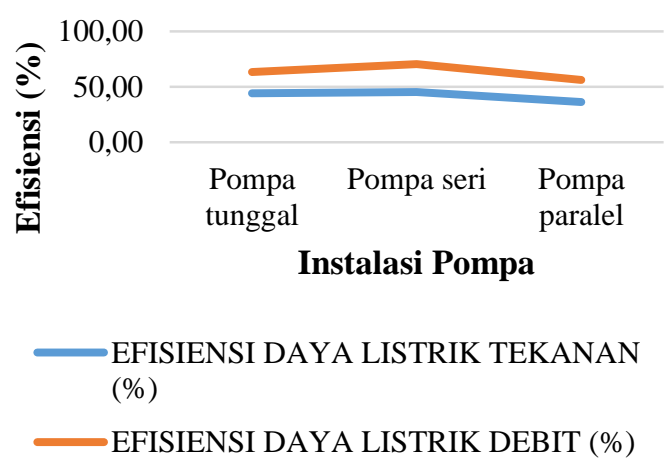

Gambar 9. Grafik hubungan instalasi pompa terhadap efisiensi daya listrik

\section{Kesimpulan}

Instalasi pompa seri tidak memberikan pengaruh terhadap peningkatan debit aliran, namun sangat berpengaruh terhadap peningkatkan tekanan dan daya hidrolik pompa. Sedangkan instalasi pompa paralel sangat berpengaruh terhadap peningkatan debit aliran namun tidak memberikan pengaruh terhadap peningkatan tekanan dan daya hirolik pompa. Hasil perhitungan didapatkan bahwa debit aliran yang dihasilkan dari instalasi pompa seri adalah $0.000450 \mathrm{~m}^{3} / \mathrm{dt}$, sedangkan debit aliran yang dihasilkan dari instalasi pompa paralel adalah $0.000769 \mathrm{~m}^{3} / \mathrm{dt}$. Hasil pengukuran diketahui bahwa tekanan air pada instalasi pompa seri adalah 80 psi sedangkan tekanan air pada instalasi pompa paralel adalah 40 psi. Hasil perhitungan daya hidrolik pompa pada instalasi pompa seri adalah 248,28 Watt, sedangakan daya hidrolik pompa pada instalasi pompa paralel adalah 198,2 Watt. Efisiensi penggunaan daya listrik pada instalasi pompa seri lebih tinggi dibanding pada instalasi pompa paralel. Hasil perhitungan didapatkan bahwa efisiensi penggunaan daya listrik saat pengukuran debit aliran pada instalasi pompa seri adalah $70,53 \%$, sedangkan efisiensi pada instalasi pompa paralel adalah 56,3\%. Efisiensi penggunaan daya listrik saat pengukuran tekanan air pada instalasi pompa seri adalah 45,14 \%, 
sedangkan efisiensi pada instalasi pompa paralel adalah $36,03 \%$.

\section{Referensi}

[1] Mustakim, "Pengaruh Kecepatan Sudut Terhadap Efisiensi," Jurnal teknik Mesin Univ. Muhammadiyah Metro, vol. 4, no. 2, pp. 79-83, 2015.

[2] Rachmat Subagio, Muchsin, Rezeky Aulia, "Analisis Karakteristik Pompa Sentrifugal Dengan Sistem Seri dan Paralel," Jurnal Teknologi Technoscientia, vol. 5, no. 2, pp. 121, 2013.

[3] I. Febrianto, M. Khabib, and B. S. Nugraha, "Perancangan Sistem Pompa Paralel Dengan Daya Bervariasi Untuk Meningkatkan Kapasitas Air," J. Crankshaft, vol. 1, no. 1, pp. 49-54, 2018.

[4] R. Y. Pradhana and E. Widodo, "Analisa Pengaruh Variasi Diameter Pipa Tekan Pvc Pada Pompa Aksial Untuk Kecepatan Gaya Dorong Air," vol. 2, no. 1, pp. 37-43, 2017.

[5] Subroto, Shodiqin, "Pengaruh Volume Tabung Tekan Terhadap Unjuk Kerja Pompa Hidram," Jurnal Ilmiah Teknik Mesin, vol. 12. No. 1. pp. 20-26, 2015.

[6] Siswadi, "Analisis Tekanan Pompa Terhadap Debit Air," Jurnal IlmuIlmu Teknik, vol. 11, No. 3, pp. 3946, 2015.

[7] Thoharudin, Arif. S.N, Stefanus. "Optimasi Tinggi Tekan dan Efisiensi Pompa Sentrifugal dengan Perubahan Jumlah Sudu Impeler dan Sudut Sudu Keluar Impeler $\left(\beta_{2}\right)$ Menggunakan Simulasi Computationnal Fluida Dynamics," Proseding Seminar Nasional Aplikasi Sains dan teknologi (SNAST), Yogyakarta, 2014.

[8] Sularso, Haruo Tahara, "Pompa dan Kompresor," Pradya Paramita, Jakarta. Cetakan Ketujuh, 2000. 